\title{
Rich, S. (Ed.) (2014). International Perspectives on Teaching English to Young Learners. Houndmills: Palgrave Macmillian, 206 p., ISBN 978-1-137-02321-6
}

Reviewed by BARBARA LESNIČAR

Edited by Sarah Rich, this book gives the reader a rich insight into a phenomenon that has appeared in the $21^{\text {st }}$ century, the teaching of English to young learners (TEYL).

Sarah Rich has worked in the field of TESOL for more than 30 years. She is an experienced teacher, who has taught worldwide and holds an honorary fellow position at the University of Exeter. She is currently employed as an educational advisor for the Ministry of Education of Oman, where she is responsible for the in-service training of primary and secondary school English teachers.

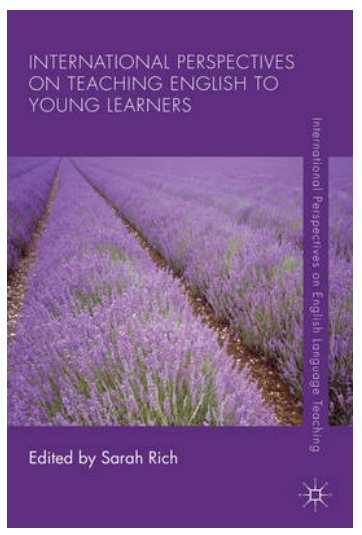

\section{Contributors}

Wendy Arnold is an experienced TESOL teacher, material writer and teacher educator. She holds an MA in Teaching English to Young Learners, a postgraduate certificate, and both the CELTA and the CELTYL. Among other things, she cooperates with the British Council and she was also part of the team that won the Middle East and North Africa Kids Read project.

Janice Bland is a visiting professor at the University of Vechta, Lower Saxony. She has been both a primary and secondary school teacher, as well as an adult educator. She joined the English department of the University of Hildesheim in 2007. Her research interests include children's literature in education, drama and creative writing.

Zehang Chen is an associate professor and the Chair of the English Department at Beijing Normal University in China. Her research interests cover teaching methodology, material development, e-learning, etc., and she has been involved in many projects.

Alina Gamboa has a master's degree in International Political Economy and $\mathrm{PhD}$ in Politics. Her work is linked to the development policy focused on 
education.

Brian Gaynor is Associate Professor of English at Muroran University in Japan. He has taught at all levels and is currently the coordinator of the Teaching Children special interest group of the Japan Association of Language Teachers. His work concentrates on the interaction between language policy and teaching pedagogy in EFL.

Sang Ah Sarah Jeon has taught English to young learners in Korea and China for nine years. She is especially interested in computer-assisted language learning.

Caroline Linse is a senior lecturer at Queen's University in Belfast. She has worked in various contexts associated with ESL and EFL programmes worldwide. Her current research includes connections between schools and homes, with a focus on interlingual families.

Leketi Makalela is Associate Professor and Deputy Head of the Division of Languages, Literacies and Literatures at the University of Witwatersrand in South Africa. He is a researcher in literacy development, language policy and planning, as well as World Englishes.

Mohammad Manasresh is an experienced language educator in Qatar. He supports teachers in their professional development at the Qatar University. He holds a master's degree in TESOL.

Shelagh Rixon has a career in English language teaching, teacher education and material writing. She spent 16 years at the British Council in various roles and has recently obtained a doctorate in the area of early literacy teaching to Young Learners of English.

Elzbieta Sowa is a graduate of the Warshaw School of Social Sciences and Humanities in applied linguistics. She has been involved in teaching English to young children for a number of years, and she is currently completing her doctorate at the University of Exeter in the UK.

Qiang Wang is a professor and director of the School of Foreign Languages in China. She is interested in English curriculum reform in basic education, ELT methodology and action research. In the past ten years, she has co-headed national English curriculum development in China.

As mentioned above, TEYL has become very popular in the last fifteen years. The reasons for this range from purely economic issues to the fact that English has become the lingua franca of international communication in almost all areas of professional and private life. Teachers dealing with young learners in their pedagogic practice should therefore be aware of the fact that although dealing with this age group (6-14 years of age) is very demanding for 
them as educators, this period of language instruction is crucial for foreign language learners.

International Perspectives on Teaching English to Young Learners is a volume of articles written by contributors with various professional backgrounds and rich experience in the field, enabling the reader to better understand precisely who young learners are. The different perspectives of a number of the articles in this volume also explain the emergence of TEYL as a global phenomenon, from the historical, political and economic reasons, to the fact that English is often a primary means of communication between linguistically and culturally diverse communities within many nation states.

The reader can find explanations of what an early start in foreign language learning can achieve, including certain potential long-term advantages, notably native-speaker-like pronunciation. In addition, particular emphasis is placed on appropriate pedagogy for TEYL.

The selection of practitioner inquiries into TEYL included in this volume meet certain criteria:

- they are representative of the enormously diverse nature of TEYL around the world;

- $\quad$ they represent contexts in which English is taught as a foreign language;

- they identify a wide range of issues and challenges facing TEYL educators around the globe;

- they generate innovative responses that are of broad interest to the global TEYL community;

- $\quad$ they stimulate debate for furthering our understanding of TEYL.

\section{Organisation of the Volume}

The nine chapters are written by professionals who have an investment in TEYL, whether as teachers, teacher educators, material writers or academics in Europe, Africa, the Middle East, Latin America and Asia. Their accounts focus on TEYL in early primary education through to the teaching of young adolescents of 13-14 years of age.

The topics covered in these chapters take into consideration important issues raised by the authors in the context of their own experiences. They are grouped into three main parts that reflect some of the key cross-cutting themes they cover. 


\section{Part I: Starting points for an inquiry into TEYL peda- gogic practice}

The first three chapters, by Arnold and Rixon, Chen and Wang, and Gaynor, deal with a critically informed understanding of TEYL practice.

Arnold and Rixon focus on teaching interventions that could accelerate young learners' development towards an ability to understand written texts. The authors address difficulty levels, the impacts of integrating an extended graded reading scheme, and the bridges we need to cross to build a culturally sensitive approach to literacy development. This process is illustrated by an extensive reading scheme undertaken with young learners of English in Hong Kong, who went from learning about sound-symbol correspondences, then moved to textlevel work and finally changed learning to read to reading to learn. This chapter also identifies key issues and priorities in helping young leaners to read in English, distinguishing between learning to read in English as a first language (REL1) and learning to read in English as a second or foreign language (REYL). Research shows that in many contexts learners for whom English is a foreign language receive little support for their English reading development. On the one hand, there is a lack of ELT reading material, while, on the other hand, teachers need to invest more time in reading instruction.

Chen and Wang highlight the importance of interaction between teachers and learners. The findings of their research on interactional practices in EFL primary classrooms in China stress the benefits of good relationships between young learners and their educators, as well as the importance of interactional practices in a teaching context. The research involved teachers and children in years 1-6 in two primary schools in Beijing. For the purpose of the study, 11 lessons were selected to be transcribed and used as a representative sample. The learners were grouped into three stages according to their age (6-11) and grade (1-6). The data seems to reveal that the interaction between teachers and younger children (grades 1-2) is not of a very high quality. However, as the children's language develops, the interaction becomes more effective and encourages language creation.

Gaynor points out the tensions between language policy inspirations and practical classroom realities. He describes the situation in Japan, and in this context highlights homeroom teachers who are expected to plan their lessons and develop material at the same time. These teachers are also encouraged to make foreign language teaching motivating and at the same time challenging and relevant to children. Another issue mentioned in this chapter is the age of instruction and the ongoing concern in Japan that learning English will 
affect students' Japanese language ability and sense of Japanese identity. The area in which the tension between policy and practice is most evident is the assumption concerning teachers' expertise. Teachers are responsible for course development, but, as the author claims, they in fact use text books and teachers' manuals. This is due to a lack of in-service training, as well as a lack of detailed pedagogical knowledge of teaching English.

\section{Part II: TEYL in a globalised world: New opportunities and new challenges}

The majority of chapters in this part deal with the ways in which globalisation influences TEYL educators. Due to the increasing flow of information, educators have to cope with interculturality, while at the same time dealing with the changing educational landscapes brought about by technology.

Jeon considers the ways in which increased globalisation, particularly via technology, has increased the amount of exposure to informal English learning opportunities for all EFL learners, including young learners. She describes the situation in Korea and shares the concerns of many educators and parents regarding the amount of time young learners spend in uncensored online activity. The results of the study reported in this chapter suggest the steps to be taken to identify out-of-class learning opportunities for young learners, and how curricula can take advantage of these new challenges, which include identities in gaming communities.

Sowa reflects on the importance of supporting teachers in promoting intercultural awareness-raising with young learners. Exploring diversity at home could be an important way to create meaningful intercultural encounters for young learners. She points out that these opportunities should be addressed in teacher education programmes. In her investigation, she mentions a number of possible ways to promote children's intercultural awareness, from European initiatives and the European Language Label Competition, to E-Twinning. Sowa describes these initiatives, as well as presenting four Polish teachers who have effectively exploited the resources and professional development opportunities.

Linse and Gamboa write about linguistic capital and how to respect children's plurilingualism in the English language classroom. Unfortunately, in many settings, plurilingualism is not currently included in national policy. In this chapter, the authors propose a framework that can benefit all stakeholders in children's ELT education, including parents, educators, policy makers, researchers and finally the children themselves. They justify the use of the framework with five main reasons: children's linguistic identity, the bond between 
homes and schools, the use of varied linguistic contexts, contextual issues, and finally vital issues regarding young learners' linguistic capital and plurilingualism. The authors offer this framework as a means to help actualise plurilingual agendas in the young learner EFL classroom in a variety of different settings worldwide.

\section{Part III: Introducing innovations in TEYL practice}

The three chapters included in this part describe how educators around the world are trying to implement innovations in their practice.

Makalela deals with the benefits of a biliteracy strategy to encourage children's foreign language reading proficiency. He highlights the biliteracy print environment, creating partnerships between schools and parents as well as a sensitivity towards the local culture. In this chapter, he mentions the research evidence on how the native language supports foreign language reading development. His reading intervention study, which took place in a remote rural school in the Limpopo Province of South Africa, tries to demonstrate the importance of bilingual pedagogic strategies.

Bland mentions a number of different approaches to drama in the TEYL classroom. She argues that drama has considerable potential for bridging and bonding, as well as being able to energise teacher education. In this chapter, she describes the first interschool Drama Workshop and the subsequent Interactive Theatre project that she developed to help support student teachers' understanding of the value of drama with young learners in Germany.

Manasresh points out some ways of improving the use of ICT in TEYL in Qatar. He argues that using ICT has a number of documented benefits for young English learners. In his opinion, it is also essential to build a positive whole-school culture to ensure the effective implementation of innovations in teaching English to young learners. Manasresh conducted action research in schools in Qatar. The research comprised three main stages: planning, acting and evaluation. The purpose of the first stage was to develop a deeper understanding of the views and experiences of young teenagers (aged 13-14), the second was about intervention, and the last stage involved reflection on the ICT listening intervention and on the action research process. The intervention was designed to provide learners with an opportunity to develop their listening skills through ICT activities. 


\section{To Conclude}

In the last 15 years, the teaching of English as an additional language to young learners has grown very rapidly. It has become a truly global phenomenon, with huge numbers of young learners. The fresh insights this volume offers will help teachers of young learners to cope with different challenges in their day-to-day practice. Several contributors also draw attention to the importance of seeking multiple-stakeholder perspectives in research into TEYL. Bearing all of the above in mind, it is evident that global dialogue about TEYL is not only necessary, but is also beneficial to our field.

\section{References}

Arnold, W. H., \& Rixon, S. (2008). Materials for teaching English to young learners. In B. Tomlinson (Ed.), English Language Teaching Materials: A critical Review (pp. 59-74). London: Continuum. 